\section{ON BLACK SOAP FILMS}

$\mathrm{T} \mathrm{T}$ is a matter of general knowledge that a very thin plate of a transparent substance exhibits colours, the tints of which depend upon the angle of incidence of the light by which it is viewed, and also upon its thickness and refractive index, and that these "colours of thin plates "were classified by Newton and divided by him into orders. If, however, such a plate is of less than a certain thickness, it appears black whatever the angle of incidence of the light may be, and its colour, therefore, gives us no indication of its thickness, except that it must be less than a particular value.

With a well-made soap-solution it is by no means difficult to obtain a film thin enough to appear black, and special interest attaches to observations made on it when in this state of extreme tenuity, as the thinner it becomes the more nearly must its thickness be comparable with the distance at which the forces exerted upon one another by the molecules of which it is composed cease to be sensible. Now under whatever conditions a film which is part black may have been formed, and whatever its shape may be, a very rapid and remarkable change of thickness invariably (as far as the writer's experience goes) occurs at the boundary which divides the black from the coloured portion of the film.

It is indeed true that contiguous portions of films are often of different thicknesses. Thus, when a bubble is first blown, streams of various colouts circulate rapidly over all its surface, but as a rule, these miniature convulsions cease in a short time, and the colours appear in regular order from top to bottom, each tint shading off gradually into those which precede and follow it. Sometimcs, too, and especially when a film becomes very thin, specks of a slightly different colour from the rest are observed moving upon its surface in paths which are often very regular. Thus in a cylindrical film which had been formed several hours and the top of which had become black, while the rest exhibited the blue of the second order, flakes of a deeper blue than the main body of the film were seen to move rapidly for many minutes in such a way as to indicate that a regular circulation was kept up in the film. Two horizontal streams moved in opposite directions round the base of the cylinder; at their metting-point they united, and the direction of the current became vertical, but on approaching the boundary of the black, the stream again bifurcated, and separate currents flowed in opposite directions round the upper edge of the blue, which again uniting on the other side of the cylinder, flowed down to the base and resumed their original directions. Slight differences in the temperature of different parts of the film would sufficiently explain these currents, which are only mentioned herel because the coloured flakes by which they were rendered conspicuous proved the existence of inequalities in the thickness of the film. These and the other variations in thickness referred to above, are, however, slight compared with those which are often observed at the edge of the black, as to the naked eye whole orders of colours (which can, however, in general be seen by means of a microscope) may appear to be missing between the black and the portion of the film which is in contact with it. Thus, in one case which has been noted, the latter must have been fourteen times, and very probably was more than forty times, thicker than the black itself.

But even when the colour next the black is the white of the first order, we do not observe, as we should if the change in thickness were very gradual, an undefined boundary between the two, shifting with every variation of the angle of incidence of the light by which it is viewed, but rather a definite line of demarcation ruled, as it were, across the film, the position of which is independent of the direction of the incident light, and at which the change of thickness, if much less than that observed in the extreme case above cited, is nevertheless very considerable.

Rotb, then, by its comparative magnitude and by the constancy with which it recurs, this phenomenon seems to suggest some special connection between the formation of the black portion of the film and the molecular forces which are at play in the liquid of which it is composed.

At the edge of the black itself, however, optical methods fail, as above explained, to give us any further help in investigating the form of the film, but some information has been obtained on this point in the course of a series of experiments on the electrical resistance of soap films, upon which Prof. Reinold and the author of this article are engaged, which they have recently made the subject of a communication to the Royal Society. To determine the thickness of a uniform soap film by measuring its electrical resistance and (having previously determined the specific resistance of the liquid of which it is composed) applying Ohm's law that the resistance of a homogeneous conductor varies inversely as its section may at first appear a simple problem; but at the outset the difficulty arises that the molecules of a hiquid which lie very near the surface are necessarily in a different state from those in the interior. The latter are subjected to the action of other molecules which are on the average distributed symmetrically around them, while the greater number of molecules which can exert any influence on the formier are situated on one side only. Hence the surface of a liquid differs in its physical properties from the intericr. and there is no guarantee that the electrical resistance of the liquid in mass is the same as that of a very thin film skimmed off its surface. But although Ohm's law cannot be applied to the case of a very thin film with any certainty that the numbers obtained by its aid will be correct, and the electrical method fails to give thoroughly reliable information as to the thickness of a black fln, yet it is possible by experimenting on a film as it gradually thins and the black portion increases in size, to learn from its electrical resistance whether the thickne: s of the black portion is constant, or whether, as is ordi narily the case with the rest of the films, it is thinner above than below, and by repeating the investigation with different films to determine whether the thickness of a black film depends upon the varying circumstances of its formation. To investigate this question fully will require more time than the authors of the paper above referred to have, as yet, been able to devole to it, but they have obtained very consistent and definite results in the experiments they have already made. The liquid used was M. Plateau's "liyuide glycerique," with three parts of potassium nitrate added to every roo parts of water to improve the conductivity.

The apparatus employed consisted essentially of a glass cylinder about $\mathrm{I} 6 \mathrm{~cm}$. high fitted with an ebonite cover, through the centre of which passed a brass tube which could be raised or depressed at pleasure, and was retained in its position by friction.

To the lower end of the tube was attached a circular brass plate, to which was soldered a ring of stout platinum foil $33.51 \mathrm{~mm}$. in diameter.

A platinum crucible, the mouth of which was of the same diameter as the ring was placed at the bottom of the glass vessel in a little dish containing mercury. When the apparatus was used, a little of the liquid was poured into the glass vessel and into the platinum crucible, in order to prevent the film thinning by evaporation; a piece of india-rubber tubing provided with a pinch-cock was attached to the upper end of the brass tube, and a plane fim having been formed on the platinum ring was blown out, through the tube, into a bubble which, when large enough, adhered to the rim of the crucible. The quantity of air inside the bubble and the position of the various parts of the apparatus were then adjusted so as 
to makc the bubble as accurately cylinelrical as pos. sible.

A current could be passed through the film by attaching wires to two binding screws, one of which "as affixed to the brass tube, while the other, attached to the ebonite cover, was in conducting communication with the crucible by means of a platinum wire, which dipped into the mercury with which it was surrounded.

This piece of apparatus was included in the arm of a Wheatstone's bridge, by means of which and a delicate reflecting galvanometer the resistance of the film was measured. As the latter continually altered and generally slowly increased, the known resistance on the bridge was made up to a certain amount, and the moment when the resistance of the cylinder became equal to it noted. The part of the total resistance thus measured, which was due to the coloured portions of the films was calculated on the assumption that Ohm's law held good, a process which made it necessary to determine the shapes of the films, which increased its thickness from above to below.

This was done by measuring with a cathetometer the breadths of the bands of colour displayed by the film when viewed by light incident at $45^{\circ}$, and noting the time at which each observation was taken. This operation was performed at least twice, and thus the rate of motion of the bands of colour was determined, from which data their positions and the form of the film could be calculated for the moments at which the electrical observations were made.

The result of these measurements was curious and will perhaps be best understood by means of the figure. The curves there given show the thicknesses of all parts of a particular film at the hours named. The upper parts represent the black portions of the films, the lower correspond to the coloured portions, and the sudden change in thickness between the two is well marked. The curves also illustrate very well the phenomena generally observed aiter the black began to form, namely, that the portion of the film in contact with it became thicker, though never thicker than any of the lower parts of the film, which, on the other hand, continued to become thinner, 50 that at last the whole assumed one uniform tint, which changed but slowly, and sometimes in such a manner as to indicate an increase in thickress. This latter phenomenon is due to absorption of moisture from the air, but it seems not unlikely that the thickening observed at the lower edge of the black may have been in part due to the fact that the sudden decrease in thickness caused by the formation of the black portion of the film must necessitate the rapid removal of a comparatively large quantity of liquid from its lower edge. The curves given in the figure, together with all the others

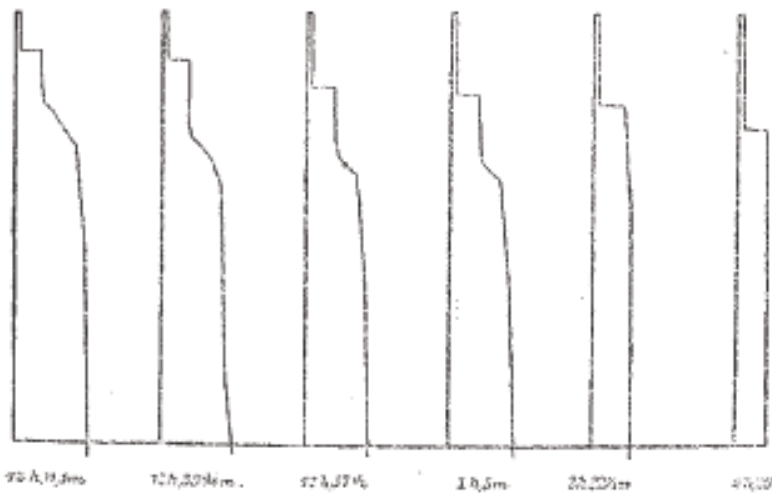

drawn from the data acquired, prove that the coloured parts of the films observed did not increase regularly in thickness from top to bottom, but that rapid changes occurred somewhat similar to, though far less marked than, that observed at the lower edge of the black. Some films thicker than those from which the figure was drawn showed two such shoulders as those curves exhibit below the black, and it was remarked that a rapid change of slope in the surface of the film generally began at points where its thickness was such as to cause it to show the yellow of the second order when seen through the telescope of the cathetometer. The thicknesses of the films are necessarily represented on a much larger scale than their lengths, as the latter would cover many yards of paper if magnified to the same degree as the former. Hence the figures give only a very exaggerated representation of the forms of the films. For instance, in the case represented in the last figure, the difference in thickness between the black and the rest of the film, which was the yellow of the second order, was certainly not greater than 320 -millionths of a millimetre. If, now, this increase in thickness took place in one-hundredth of a millimetre (a distance which would be inappreciable on the scale of the figures), the colours of the first order and those of the second inside the yellow would probably not have been visible if crowded together in so small a space, yet the transition from the black to the yellow would, in such a case, be made by an easy slope of 3 in 100, instead of by the abrupt change represented. We are thus, in all probability, dealing throughout with very small curvatures, and it is only the extraordinary sensitiveness of the tests of the thickness of a film at our command which enables us to detect the slight changes of slope which occur.

Having thus determined the shape of the coloured portion of a film it is easy to calculate its resistance, and by subtracting this calculated result from the observed total resistance of the film to deduce that of the black part alone, and thence to calculate the resistance of a ring of the black of the diameter of the crucible, and $1 \mathrm{~mm}$. broad. If the number so obtained varies in different experiments, the inference is that either the thickness of the black portions of the films varies, or that the assumption that Ohm's law was applicable to the rest of the film was incorrect; if it is constant we draw the double conclusion that the thickness of a black fitm is constant, and that the coloured films obey Ohm's law. Such a method affords, however, only an unsatisfactory test of the latter of these points, as the resistance of the coloured portion of a film is in general so small a fraction of that of the black part, that a considerable apparent divergence from Obm's law, and consequent error in its calculated value, would not produce much error in the resistance of the black film.

With regard to the first point, however, viz, the variations to which the thickness of a black film is subject, the experiments furnish some more trustworthy information. Five cylinders were observed on five different days, and in all thirty-six determinations of the resistances of black films were made. The breadth of the black ring varied on different occasions between $\mathrm{r}^{\prime} 4 \mathrm{~m}, \mathrm{~m}$. and $11.87 \mathrm{~m}, \mathrm{~m}$, and the total resistances measured lay between 3'7 and 22 megohms. The highest and lowest values of the resistance of a ring of the black $1 \mathrm{~mm}$. broad obtained from individual experiments, differ from one another by about eleven per cent. of the mean value, but the means of each day's resuits agree to within about five per cent., and the means of four out of the five days' results agree to vithin two-and-a-half per cent. We thus learn that the thickness of the black films formed in the same manner and with the same apparatus, varied very little on the different occasions on which they were observed. By treating the experiments in this way, we mingle together indiscriminately, all the observations obtained from any one cylinder, whatever the breadth of the black film may have been. If, however, it diminished in thickness from below to above, we should expect that observations taken when the black part of a film was large and thereforc, on the average, thinner, would, on the 
whole, give higher values for the resistances than those taken when it was small.

Accordingly, the results were grouped according to the breadth of the black film, and it was found that the mean value of the resistance of a ring $1 \mathrm{~mm}$. broad, deduced from experiments made when the breadth of the black was between

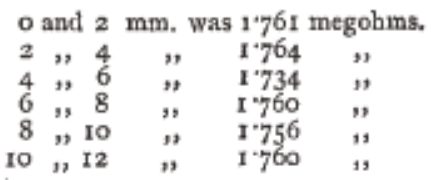

These numbers prove that the thickness of the black ring is independent of its breadth.

It was, however, thought possible that the thickness of the black film might be affected by that of the coloured portion of the film which appeared to be in contact with it, and accordingly the results were once more grouped with reference to that colour only.

The mean value of the resistances when the colour next to the black was the

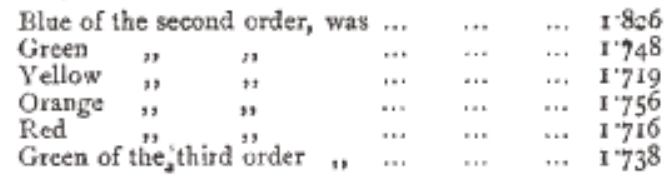

The first of these numbers is considerably larger than the rest, but it is deduced in great part from a high set of measurements which were obtained during the observations on the first cylinder. Equally high values were, however, obtained later on the same day when the colour next to the black was the orange of the second order, and on the only other occasion on which an observation was taken with the blue of the second order in contact with the black, the number obtained was 1760 . Hence the high value, 1826 , does not $5 \mathrm{~cm}$ to have any special significance, and we conclude that the thickness of the black is independent of the portion of the film which appears to the naked eye to be in immediate contact with it.

The principal error with which these experiments are probably affected is due to the fact that the lower boundary of the black part of a film was not always strictly horizontal. When this was noticed to be the case, the breadth of the black ring was measured in several parts, and a mean value was deduced, but it was difficult for the observer to determine whether or no the further edge of the black was below that nearer to him. In spite, hovever, of this and the other possible errors of experiment, the numbers obtained certainily prove that the thickness of a black film is uniform, and is very approximately constant under such variations of circumstance as those to which the films observed were exposed. One other point may be worthy of notice. The mean value of the resistance of a black ring $I \mathrm{~mm}$. broad deduced from all the experiments was $1,750,000$ ohms, and by applying Ohm's law to this we obtain for the thickness of the black film twelve-millionths of a millimetre. This value, which must be received with the cautions given above, is only one-third of that at which a film of the solution used would begin to appear black, and would make the thickness of the film one-forty-ninth part of the wave-length of $D$.

As Prof. Reinold and the writer are at present engaged in investigating the question of the magnitude of the radius of molecular attraction, a consideration of the various speculations as to molecular magnitudes, to which these experiments lead must be for the present postponed.

A. W. RÜCKER

\section{RAINFALL IN SOUTH INDIA}

THE probability of another failure of rain and consequent famine in South India gives to any facts connected with rainfall in that country so great an interest that I will not delay longer the publication of a result obtained by me several months ago in a paper which would have been presented to the Royal Society last session, but for the desire to complete it with some details expected by me from India.

Whether the amount of rain follows the decennial law or not, all the known causes of variation will pass, it may be believed, through all their phases within ten years; so that the yearly mean rainfall deduced fiom ten years' observations should give a considerable approximation to the mean from any series however long. Any deviations from this result would be expected to be small and irregular. The fact is otherwise, if the observations at Trevandrum, on the west coast, and at Madras on the east coast, may be taken (as has been done) for approximate representations of the variations for the country around.

The Trevandrum series of observations includes the years 1838 to 1876 . Taking the stums of rainfall for each ten years (1838-47, $1839-48$, and so on), it appears that the amount was a maximum in the ten years 1843-52, and equal to $76 \mathrm{r}$ inches, from which time it has gradually diminished (with occasional slight increases) till now, $1867-76$, when it is only 562 inches; or the yearly mean rainfall during the last ten years was nearly 20 inches less than a quarter of a century ago.

When we examine the Madras observations we find a quite similar result. The Madras series includes the period 1813 to 1876 : the ten-yearly sum of rain was a maximum in $1818-27$, and equal to 555 inches; it diminished to a minimum in $1828-37$, and equal to 382 inches ; increased, as at Trevandrum, to a maximum in 1843-52, and equal to 583 inches ; diminishing thence to 396 inches in $1860-69$. The agreement with Trevandrum is complete till this period; but the sum increased at Madras to 510 inches in 1865-74, diminished thence till now, whereas at Trevandrum the diminution has continued to the present time.

If we compare the diminutions at the two stations while they agreed, we find-

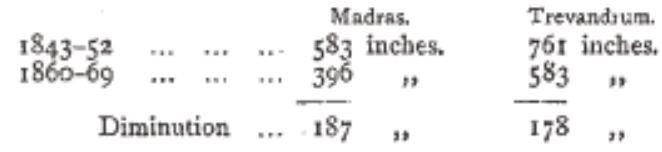

Or at both stations a diminution of the yearly mean rainfall of about is inches. It will be of importance to ascertain whether this diminution has been experienced at more northern stations.

The yearly rainfall on the west coast of India, near Cape Comorin, was about 26 inches in 1844 ; it increased to about 70 inches at Trevandrum, thence to about 120 inches at Cananore, diminishing at Bombay and farther north, the maximum fall occurring somewhere between Cochin and Bombay. This variation does not depend wholly at least on the nearness of the stations to the range of the Ghats. It appears that the great atmospheric current sweeping over the Indian Ocean charged with vapour during the monsoons has a central current of maximum vapour depth or of velocity. If we can imagine that this central current shifts on the whole northwards from year to year for some time, the stations to the south will receive less and less rain, while those to the north will receive more; the total precipitation might thus remain the same. If we could suppose such a movement of the vapour masses to obey a law like that of the sunspots (and something resembling this has been found by me in the investigations for the isobaric lines and windcurrents in the British Isles), then we should find in such 